- This qualitative study has identified a range of personal, organisational and policy factors which influence reported change in GDPs' work patterns.

- Barriers to change need to be addressed to enable GDPs to respond to the needs of their patients and the new organisational structures which are soon to be introduced.

\title{
The facilitating factors and barriers influencing change in dental practice in a sample of English general dental practitioners
}

\author{
R. Watt, ${ }^{1}$ P. McGlone, ${ }^{2}$ D. Evans, ${ }^{3}$ S. Boulton, ${ }_{1}^{4}$ J. Jacobs, ${ }^{5}$ S. Graham, ${ }^{6}$ T. Appleton, ${ }^{7}$ S. Perry ${ }^{8}$ and A. Sheiham ${ }^{9}$
}

\begin{abstract}
Aim The objective of this study was to investigate the barriers and facilitators to change in dental practices among a sample of general dental practitioners (GDPs) from three regions of England.

Method In-depth face-to-face interviews with $60 \mathrm{GDPs}$ were undertaken. The sample was selected from a group of 317 GDPs who had completed a questionnaire in the first phase of this study. The participants were selected to reflect diversity regarding the number and extent of selfreported changes reported in the questionnaire, and personal and practice characteristics. Of the 92 attempted contacts, 60 (65\%) of the interviews were successfully completed. The interview schedule formed the basis of the interview. All the interviews and notes were transferred on to NUD*IST OSR version 4, a qualitative analysis package.

Results No single factor was identified as being more important than another in facilitating change. The main facilitators for change were: financial factors, regular patient attendance, particularly a core patient group, staff loyalty, having regular staff meetings and open communication and having access to peer support. The main barriers to change were the reverse of the facilitators plus not having a financial stakehold in the practice.

Conclusions A range of factors were identified as influencing change in general dental practice. These include GDPs' attitudes and experience of change, patient factors, organisational issues, contact with peers and access to appropriate training courses.
\end{abstract}

\section{INTRODUCTION}

The current emphasis on improved quality, evidence-based practice, clinical governance and continuing professional development requires the dental profession to critically review the value

${ }^{1 *}$ Reader, ${ }^{2}$ Research Fellow, ${ }^{9}$ Professor, Department of Epidemiology and Public Health, University College London; ${ }^{3}$ Consultant in Dental Public Health, Department of Dental Public Health, North Tyneside Primary Care Trust, Benfield Road, Newcastle upon Tyne: ${ }^{4}$ Consultant in Dental Public Health, Department of Dental Public Health, Coventry Primary Care Trust, Greyfrairs Lane, Coventry; ${ }^{5}$ Consultant in Dental Public Health, Department of Dental Public Health, Islington Primary Care Trust, London; ${ }^{6}$ GDP, North Shields, Tyne and Wear ${ }^{7}$ GDP, Queens Road, St Peter Port, Guernsey; ${ }^{8}$ GDP, Westmount Road, Eltham, London *Correspondence to: R. Watt, Department of Epidemiology and Public Health, University College London WC1E 6BT

Email:r.watt@ucl.ac.uk

\section{Refereed paper}

Received 05.03.03; Accepted 11.11.03

doi:10.1038/sj.bdj.4811748

๑) British Dental Journal 2004; 197: 485-489 of their practice and implement change when necessary. ${ }^{1-3}$ The NHS Centre for Reviews and Dissemination suggest that 'any attempt to bring about change should first involve a diagnostic analysis to identify factors likely to influence the proposed change. Choice of dissemination and implementation interventions should be guided by the diagnostic analysis and informed by knowledge of relevant research. ${ }^{4}$ One way to carry out a diagnostic analysis is by understanding the barriers that may hinder the adoption of new practices. A recently published paper reported in quantitative terms the extent and nature of self reported change in dental practices, but only provided a few insights into the process of change. ${ }^{5}$

Research with the medical profession has identified a range of barriers to changing practices. They include the knowledge and attitudes of the practitioner, patient factors, practice environment, educational experience and features of the healthcare system. ${ }^{6,7} \mathrm{~A}$ study on barriers to evidence-based medical practice found that the attitude of the practitioner towards evidence-based practice, awareness and perceived usefulness of relevant journals, ability to access relevant databases and a lack of understanding of the technical terms used influenced whether they practised evidence-based medicine. ${ }^{8}$

A recently published paper described the practice and personal characteristics that lead to change in this sample. ${ }^{5}$ These findings were similar to previous research on adoption of specific clinical dental techniques. For example, dentists' use of dental sealants was related to the type of practice in which they worked, the practitioners age, the number of journal articles they read, the number of local dental meetings they attended, their integration in the dental community, their knowledge and attitudes towards sealants, and their preventive orientation. ${ }^{9}$ A study assessing dentists' changes in use of endodontic techniques identified the following factors as being influential: expected clinical outcome; patients' expectations; anxieties arising from lack of expertise; ways of managing time' cost pressures and payment structures and attitudes to postgraduate qualifications. ${ }^{10}$

Understanding the facilitating factors and obstacles to change in dental practice is critical for the development of implementation strategies to assist the dental profession to respond to changing demands and circumstances. The objective of this study was therefore to investigate in depth, the barriers and facilitators to change in dental practices among dental practitioners. 


\section{RESEARCH}

\section{METHODS}

This was the second part of a two-phase study assessing change in dental practices in England. The first part was a quantitative study of a sample of dentists working in three English regions. Details of the sample from phase one of the study have been previously described. ${ }^{5}$ Phase two, a qualitative study consisting of in-depth face-to-face interviews, was conducted with 60 dentists in the three regions who had completed the first phase of the study. Qualitative research is particularly suited to understanding in detail the reasons and processes behind behaviours ${ }^{11}$ and therefore provides an ideal method to understand the way in which different factors inhibits or facilitates change in dental practice.

\section{Sample}

In phase one, of the 338 respondents returning completed questionnaires 317 agreed to participate in the second phase of the study. A purposive sampling method was employed to ensure that a diverse range of GDPs were included in the second phase of the study. ${ }^{12}$ Participants were selected on the basis of the following factors: extent of self-reported change, proportion of private practice, position in practice, type of practice (single-handed or group), age and sex of practitioner, whether they had a postgraduate qualification and location of practice.

To cover the above factors an attempt was made to contact a total of 92 GDPs who had participated in the first phase of the study. No contact was made after numerous telephone calls with 16 (17\%) GDPs. Of the remaining 76, 12 refused to participate, and a further six cancelled their interviews just before they were due to take place. Therefore of the 92 attempted contacts, 60 (65\%) of the interviews were successfully completed.

\section{Data collection}

To assist in developing an interview schedule, six pilot interviews were conducted. The purpose of the schedule was to investigate the barriers to change; factors and processes that brought about change and resistance and predisposition to change. The interview schedule formed the basis of the interview, but the interview was also flexible so that issues arising during the course of the interview were followed up in subsequent interviews. All interviews were tape recorded and lasted around 60 minutes.

\section{Analysis}

All the interviews were transcribed. Notes were taken directly after each interview which formed the initial process of analysis. ${ }^{13}$ All the interviews and notes were transferred on to NUD*IST QSR version 4 , a qualitative analysis package. The interview schedule formed a basic structure for the analysis, therefore a deductive approach formed part of the analysis. In addition, a more inductive approach was also used where coding was responsive to the data from the transcripts. ${ }^{13}$ The data were constantly scrutinised to help develop explanations. ${ }^{11}$ An index system was generated through repeated reading of the text. This index system was constantly refined as an ongoing process throughout analysis. NUD*IST QSR allowed for cross tabulations between the different pieces of data to help explore deviance. The use of computerised analysis packages assists in improving the rigour of qualitative research. ${ }^{14}$ Quotes have been used to illustrate specific points and are identified by their score for change across seven areas of practice (the higher the score the higher the level of self-reported change) and the level of income generated from NHS practice.

\section{RESULTS}

\section{Profile of interviewees}

Of the 60 GDPs interviewed, 31 (52\%) practised in the North of England, 7 (12\%) were from the Midlands and 22 (37\%) were from the South of England. One third of the sample had a postgraduate

\begin{tabular}{|c|c|c|c|c|}
\hline & $\begin{array}{l}\text { Total } \\
(n=60)\end{array}$ & $\begin{array}{l}\text { North } \\
(n=31)\end{array}$ & $\begin{array}{l}\text { Midlands } \\
(n=7)\end{array}$ & $\begin{array}{l}\text { South } \\
(n=22)\end{array}$ \\
\hline $\begin{array}{l}\text { Postgraduate } \\
\text { qualifications }\end{array}$ & $32 \%(19)$ & $33 \%(10)$ & $43 \%(3)$ & $29 \%(6)$ \\
\hline Aged $<40$ yrs & $45 \%(27)$ & $52 \%(16)$ & $43 \%(3)$ & $36 \%(8)$ \\
\hline Male & $72 \%(43)$ & $68 \%(21)$ & $86 \%(6)$ & $76 \%(16)$ \\
\hline Vocational trainer & $12 \%(7)$ & $13 \%(4)$ & $14 \%(1)$ & $9 \%(2)$ \\
\hline Associate & $20 \%(12)$ & $16 \%(5)$ & $29 \%(2)$ & $23 \%(5)$ \\
\hline Sole owner & $50 \%(30)$ & $48 \%(15)$ & $71 \%(5)$ & $45 \%(10)$ \\
\hline Single-handed & $32 \%(19)$ & $29 \%(9)$ & $43 \%(3)$ & $32 \%(7)$ \\
\hline \multicolumn{5}{|c|}{ Percent private practice } \\
\hline$<20 \%$ & $48 \%(29)$ & $55 \%(17)$ & $57 \%(4)$ & $36 \%(8)$ \\
\hline $21-40 \%$ & $13 \%(8)$ & $13 \%(4)$ & $29 \%(2)$ & $36 \%(8)$ \\
\hline$>80 \%$ & $29 \%(9)$ & $3 \%(1)$ & & $36 \%(8)$ \\
\hline \multicolumn{5}{|l|}{ Change score } \\
\hline$($ Mean \pm SD $)$ & $7.8(4.4)$ & $7.9(4.8)$ & $6.5(2.9)$ & $8.0(4.31)$ \\
\hline Range & $0-17$ & $1-17$ & $1-9$ & $0-17$ \\
\hline $0-5$ & $33 \%(20)$ & $39 \%(12)$ & $29 \%(2)$ & $27 \%(6)$ \\
\hline $5.1-11$ & $42 \%(25)$ & $29 \%(9)$ & $71 \%(5)$ & $50 \%(11)$ \\
\hline $11.1-21$ & $25 \%(15)$ & $32 \%(10)$ & & $23 \%(5)$ \\
\hline
\end{tabular}

qualification and almost three-quarters were male. One fifth were associates, half were sole owners and one third were in singlehanded practices. Almost half earned less than 20\% of their income from private practice. Based upon their responses to the phase one questionnaire, one third of the sample had a change score ranging from 0-5.0 (low levels of change) and one quarter had a score for change ranging from 11.1-21 (high levels of change) (Table 1).

\section{Factors influencing change}

There was a range of barriers to change. Inevitably, many of the barriers were often the reverse of the facilitating factors. No one factor was more important than another. Rather there was an interaction between each of the factors. Table 2 illustrates the different barriers to change. Each of these is discussed separately below in the context of how they each presented as a barrier or facilitator to change.

\section{Financial factors}

The most frequently cited reason for not changing practices was economic. There were financial risks associated with changing practices. Changing practices was perceived to have a financial cost and therefore this cost had to be weighed against the benefit of the desired change. This 'cost:benefit analysis' was the main rationalisation process that was used to decide whether to adopt a specific new practice. For change to be implemented there had to be a perceived financial benefit. The financial benefits were often long-term. Most of the finance related benefits were associated with time, improved

\section{Table 2 Barriers affecting change in practices}

\section{Finance - risk of losing income}

Irregular patient attendance

Poor staff loyalty

Poor staff communication

Not having a financial stakehold

No access to peer support - neither internal or external

Personal - inertia and negative attitudes

Relying on one educational source such as journals 
efficiency, improved clinical outcome or increased patient satisfaction. However, to sustain the change, the outcome of the change had to be supported by a positive reinforcement. Many had made mistakes in changing, with negative financial consequences. They were therefore reluctant to consider change again.

'If there is nothing wrong with the old technique you think why should I bother. It would have to be for economic reasons or something that the patient expects in some way.' (100\% NHS; Change score $=3$ ).

Most who practised NHS dentistry complained about the remuneration system and the restrictions it placed upon them. For some, this often led to them carrying out a treatment at a financial loss.

Changing to predominantly private practice was often an immediate cue for change as new treatments could be offered to patients. Some investment in the surgery was usually involved when changing to a higher proportion of private practice. Offering private dentistry was also a stimulus to attending courses to learn about new techniques that were not being offered in the NHS. This was rationalised in terms of patient demands.

However, whether the move to private practice lead to patient demands increasing, was confounded by the fact that the change also gave rise to the use of new equipment and enabled practitioners to show patients what types of treatments were on offer. Not all those with a higher proportion of income from private practice changed all aspects of their practices as the changes were still rationalised in terms of costs and benefits. The perceived benefit was dependent upon knowledge, skills and personal choice rather than a full assessment of the evidence of the outcome of the change.

\section{Patients}

Patients were important forces, facilitators and barriers to change. Dentists perceived that patient expectations had increased and whilst this provided a cue for change, some reported that it had become increasingly difficult to meet their demands. For example, the threat of litigation prompted changing note taking and improving the explanations given to patients.

'...Patient awareness is becoming more, they are becoming more litigious which means I think you have to let the patients know what is going on from the beginning. You explain to them as you go along. Yes, we have therefore got more patient information literature.' (20\% NHS; Change score $=13$ )

Patients also affected treatment decisions, some would not comply with best clinical judgement and therefore were seen as a possible barrier to evidence-based practice.

'I think there is a big issue about consent of patients. Patients don't necessarily accept what the evidence is. I mean so many patients come because they want a scale. In a business atmosphere you don't turn people away.' (60\% NHS; Change score $=7$ )

A lack of concern for oral health by patients affected the motivation for change. Regular attendance was considered to be important, both in sustaining the practice and in terms of clinical decisions. Some worked in areas where there was a highly mobile population and therefore found it difficult to maintain a core base of patients. In such areas there was no positive reinforcement from patients to help initiate change and therefore the practitioner's lack of motivation for change was fuelled by patients' failure to attend for their appointments.
'...I mean there are people who will be in the chair and I am actually showing them how to clean their teeth, and they are less interested, they are not bothered, so I stop there and then. I stop wasting my breath.' (95\% NHS; Change score = 7)

\section{Organisational factors}

Organisational factors affected the process by which change could be implemented. In practices where tasks were delegated and there was a 'team' approach, the implementation of change into practice was made easier. This was dependent upon having a core group of long-term staff.

Where a 'team' approach was not adopted, the position held in the practice was one of the factors that acted both as a barrier and facilitator for change. Many associates reported that their position prevented them from making changes. Some were frustrated because they had to work within the constraints set by the practice principal. Conversely, the principals argued that the changes being advocated by some associates were unnecessary. Many did not have an organisational framework in which to discuss these issues.

The way that the practice was run affected the degree to which dentists in a group practice interacted. The interaction was important in terms of keeping up to date, and for discussing decisions with colleagues and provided cues to changing practice.

\section{Personal attitudes}

There was a certain amount of personal resistance and inertia to change reported by several of those interviewed. Barriers to change were often seen as important and were perceived as limiting the feasibility of change.

'I mean it's difficult to change, particularly when you are busy. It is quite difficult when you are set in your ways to start doing something differently. [...]. Things that we have bought in the past, there has been nothing wrong with them, but everybody has their routine of working and you find that no matter how much they wanted that, like the intra-oral camera, it doesn't get incorporated in to daily routine. Then it sits and reproaches, gosh how much it costs, we don't really use it.' (0.1\% NHS; Change score $=5$ ).

The opposite view was the optimistic attitudes and proactive approach reported by those interviewed who had changed. Whether the positive attitude was a consequence of being proactive or being proactive was a consequence of having a positive attitude is difficult to assess. Receptiveness to change was therefore not necessarily related to the characteristics of a specific dentist, but the environment that created motivation to change and the networks that stimulated change.

'Life has taught me that you cannot stay static. You have to change. You have to evolve. Things are going so quickly in front of our eyes with all these corporate ones and private practices, that if you are not running up to steam with them, you are going to be left behind'. (90\% NHS; Change score $=8)$.

'I would rather be involved in the change than have it thrust upon me. I would be just as curmudgeonly as anybody else. I am doing that just because you have told me to. I would rather be one of the people who was out there trying to be one of the people agreeing what the terms were going to be than one of the ones sitting at the back blustering on that I don't want to do that.' (98\% NHS; Change score = 17).

Being older was not a barrier to change for some. There were older practitioners who had previously been proactive and therefore had set in place the necessary facilitators that enabled 


\section{RESEARCH}

them to keep practising at a level that was similar to those that were currently changing. Older dentists who were resistant to change justified their actions by indicating that change was not always necessary. This rationalisation was based upon their experiences of past changes that were often unnecessary.

'I have just got to the stage in my career where I don't want to change...I think if things are going quite smoothly, then you don't really want to change. What is the point of changing if everything is going really well.' (95\% NHS; Change score $=1$ )

\section{Continuing professional education}

Continuing professional education played a key role in changing practices. Knowledge and information was disseminated in a variety of ways amongst practitioners. Deciding on what changes to implement was dependent upon stimuli from courses or journals, though many were dependent upon colleagues and networks for information. It was evident that those who were likely to change their working practices had greater sources of information and knowledge to justify their actions.

Journals were mentioned by most. For those who complained about a lack of time to attend courses, journals were a more important source of information. Reading journals per se did not appear to lead to change. The journals triggered new ideas and provided a stimulus for exploration. However, many questioned the relevance of what they read in the journals and its applicability to general dental practice. Many relied on 'practice-based' journals such as Dental Update, Independent Dentistry and Dental Practice as they were considered to be relevant to everyday practice. The British Dental Journal, although mentioned by many dentists, was seen as 'too academic' and the subject matter covered often too difficult to apply in general practice.

'Dry, dry, dry. Please log on to the 21 st Century. It's [BDJ] just a bit ivory tower basically. It's way too academic' (60\% private; Change score $=13$ ).

Most of the dentists interviewed complained about the quantity of literature that they received and found that they reached a state of fatigue and information overload. Many prioritised their reading to certain journals and read the abstracts and key issues rather than trying to go through the whole journal. Most of the more proactive dentists indicated that they usually heard about a specific innovation if it was successful through other means than journals. Usually the networks they had established enabled them to have access to those who were in a position to interpret the best evidence or best clinical results.

The majority of those interviewed attended courses, though the level of attendance varied widely. Some courses led to a postgraduate qualification that created an impetus for change. Many who were becoming bored with dentistry and who lacked motivation, found that a postgraduate qualification created new interest in their job and led to the pursuit of further activities. Attendance at continuing education courses also had the benefit of meeting other colleagues and sharing ideas.

Some questioned proposals to make attendance at courses compulsory. A concern was expressed that many courses were offered merely as a means of making money out of GDPs. The commercial marketing and promotion of courses were seen to support this view. The 'hands on' courses were considered useful and more likely to initiate change because they allowed participants the opportunity to handle new materials and try out new techniques without the risk of losing money if they were not considered any better.
'I did a course in occlusion, a five-day course, and that helped me tremendously in even small little issues and things that I would come across in general practice. It just raises your standard. If you didn't attend a certain course then you wouldn't know what to do and you would probably not do the right thing or you wouldn't do anything.' (45\% NHS; Change score = 13).

\section{Evidence based dentistry and quality assurance}

A high degree of scepticism was commonly expressed towards the notion of evidence-based dentistry. The main emphasis on evidence-based practice was seen to be from an academic perspective with little relevance to day-to-day clinical practice. Change was dependent upon success with handling materials irrespective of evidence of effectiveness. Furthermore, even when there was clear evidence, some made comparisons with other countries were there was conflicting evidence.

'A lot of materials that one uses are technique sensitive, so if I am using material $A$ and getting a good result, material $B$ might be scientifically and theoretically better but my usage of it might not give me as good a result as the one I am used to. Therefore, I stick to what I know.' (99\% private; Change score $=3$ ).

Auditing was used by only a small number of those interviewed. Some were involved in 'informal' auditing and explained this as adopting a critical approach to care. This was rarely collated in any formal way but played a role in clinical decisions and change. In general, there was a lack of understanding of audit and the degree to which it would be a process that could achieve change.

'I haven't done an official sort of audit, no, but I think that I work to a very high standard, even on the NHS and I mean I am critical of my work anyway. I am critical of my $x$-rays that I take. I am critical of my root canal treatments and my fillings. So I sort of haven't really had a situation where I had to think why is this happening? I haven't been prompted into doing an audit'. (45\% NHS; Change score=13).

The peer review process lead to change in some areas of practice, although the same process of implementation of change was still undertaken. For those that participated in peer review meetings, it was seen as an essential way to interact with colleagues. Some questioned the real benefits of peer review and saw it only as a reason to meet with colleagues for a social gathering.

I've done quite a few peer reviews in the past, but the funding has stopped so I haven't been doing it so much. Peer review is very good, it gives you the chance to talk about things without feeling like you're boring everyone else, and you can pick up an awful lot of information.' (50\% NHS; Change score = 10).

'It was an excuse for four or five of us to go to the pub and have $a$ beer and $a$ curry and get $£ 50$ or something like that. I suppose there are some subjects that might be worth it, but I wasn't too struck about it.' (99.9\% NHS; Change score = 11).

Barriers to participation in peer review included a lack of time, scepticism of the evidence base in dentistry and being isolated from colleagues.

'I actually think it's [peer review] a waste of time because people have got such different views on what is dentally fit and what isn't dentally fit and which way to approach things, I don't think there are standard norms in dentistry.' (1\% NHS; Change score $=7$ ). 


\section{DISCUSSION}

The qualitative data collected has provided some interesting insights into the barriers and facilitators to change within general dental practice. Sixty interviews with GDPs from across different areas of England have provided a great deal of valuable information. A diverse sample of GDPs have been interviewed. In qualitative research the sampling methodology seeks to explore differences within the sample until a saturation point is reached and no new issues emerge from the interviews. ${ }^{13}$ However, caution needs to be exercised in the interpretation of the data as the sample cannot be considered representative of GDPs across the UK. The interview data does raise a range of interesting issues relevant to understanding change in dental practice.

The most important factor influencing change was the potential financial risks associated with adopting a new practice. Those interviewed described how they considered the potential risks and benefits of changing. This rationalisation appeared to be influenced by an array of factors and was not simply based upon a scientific assessment of benefit. The influence of economic factors on health professionals' willingness to adopt new practices has been identified in previous research with both doctors and dentists. ${ }^{15,16}$ A remuneration system which limits the perceived financial risks of adopting new practices is more likely to encourage the dental profession to make desired changes.

Patient factors are a powerful influence over change. ${ }^{6,7}$ In this study patients were perceived as having both a potentially positive or negative influence. In practices with a stable patient base, where trust and rapport had been established, implementing change was more likely. This confirms the advantages for both patients and dentists of continuity in primary dental care. It also supports the importance placed upon developing good communication skills and trust to enable practitioners to fully explain treatment options. ${ }^{17}$

Organisational issues were also both a barrier and facilitator of change. In dental practices where a team approach had been adopted and good communication systems had been established, change appeared to be more easily achieved. Autonomy within the team appeared to be an important factor. Associates who were given little control over how they worked complained that change was not an option.

Unlike many other parts of the NHS, GDPs can often be very isolated from colleagues. This study has demonstrated that professional networks, both formal and informal have a major influence over change. Practitioners who did not belong to any network and were professionally isolated lacked these support mechanisms. These findings are supported by the results of a study in the north west of England which showed that the majority of GDPs turned to friends and colleagues for help and support when faced with clinical uncertainties. ${ }^{18}$

It was interesting that so many of those interviewed expressed a negative view of continuing professional development (CPD). Many courses, journals and the notion of evidence-based dentistry were considered to be too academically focused and largely irrelevant to primary dental care. This finding contrasts with the results of a recent study of Scottish primary care dentists. ${ }^{19} \mathrm{CPD}$ will only be beneficial when it is seen to be applicable and relevant to clinical practice.

A finding that may concern planners is the limited experience and indeed understanding most practitioners had of audit and peer review. The small number of the sample who had been involved in audit and peer review activities stressed the value of discussing cases with colleagues and reflecting upon different approaches to solving problems. Most of those interviewed appeared to lack critical evaluative skills that are required in audit and peer review. Government plans to promote quality assurance within the general dental services need to address this issue. ${ }^{2}$

Publication of Options for Change has established a radical agenda for the future development of primary dental care in the $\mathrm{UK}^{3}{ }^{3}$ What implications does this study have for implementing change? It is very apparent that change in general dental practice is influenced by many factors. Unless these factors are addressed directly then proposals to alter the nature of primary dental care are unlikely to be realised. The conditions or environment in which GDPs' work needs to be conducive to supporting change and innovation. Organisational systems and structures need to be established to create an environment where change is possible. ${ }^{20}$ For example, the remuneration system needs to reduce the perceived financial risks associated with change. Also, establishing supportive professional networks which create a safe setting where ideas can be exchanged and models of good practice shared, is essential to facilitate innovation. Lastly, practitioners need to be equipped with the appropriate skills to enable them to implement desired change.

This study was funded through the Primary Dental Care $R$ \& $D$ Programme. The authors would like to thank all the general dental practitioners who participated in this study.

1. Department of Health. The NHS Plan. London: The Stationery Office, 2000.

2. Department of Health. Modernising NHS Dentistry - Implementing the NHS Plan. London: Department of Health, 2000.

3. Department of Health. NHS Dentistry: Options for Change. London: Department of Health, 2002.

4. Effective health care: getting evidence into practice. NHS Centre for Reviews and Dissemination. York: University of York, 1999.

5. Watt R, McGlone P, Evans D et al. The prevalence and nature of recent self-reported changes in general dental practice in a sample of English general dental practitioners. BrDent J 2004; 197: 401-405.

6. Oxman A, Thomson M, Davis D, Haynes R. No magic bullets: a systematic review of 102 trials of interventions to improve professional practice. Can Med J 1995; 153: 1423-1431.

7. Haines A, Donald A. Making better use of research findings. Br Med J 1998; 317: 72-75.

8. McColl A Smith H, White P. Filed J. General practitioners' perceptions of the route to evidence based medicine: a questionnaire survey. Br Med J 1998; 316: 361-366.

9. Hunt R, Kohout F. Predicting the adoption of pit and fissure sealants. J Dent Res 1983; 62: 234.

10. McColl E, Smith M, Whitworth J, Seccombe G, Steele J. Barriers to improving endodontic care: the views of NHS practitioners. Br Dent J 1999; 186: 564-568.

11. Mason J. Qualitative Researching. London: Sage, 1997.

12. Boulton M, Fitzpatrick R. Qualitative methods for assessing health care. Quality Health Care 1994: 3: 107-113.

13. Pope C, Ziebland S. Mays N. Qualitative research in healthcare: Analysing qualitative data. BrMed J 2000; 320: 114-116.

14. Murphy E, Dingwall R, Greatbatch D, Parker S, Watson, P. Qualitative research methods in health technology assessment: a review of literature. Health Technol Assessment 1998; 2: 16.

15. Cabana M, Rand C, Powe N. et al. Why don't physicians follow clinical practice guidelines? A framework for improvement. J Am Med Assoc1999; 282: 1458-1468.

16. Calnan M, Silvester S, Manley G, Taylor-Gooby P. Doing business in the NHS: exploring dentists' decisions to practise in the public and private sectors. Soc Health IIIness 2000; 22: 742-764.

17. Jacob M, Plamping P. The practice of primary dental care. London: Wright, 1989

18. Iqbal A, Glenny A-M. General dental practitioners' knowledge of and attitudes towards evidence-based practice. Br Dent J 2002; 192: 587-591.

19. Leggate $M$, Russell E. Attitudes and trends of primary care dentists to continuing professional development: a report from the Scottish dental practitioners survey 2000. Br Dent J 2002; 193: 465-469.

20. Firth-Cozens J. Healthy promotion: changing behaviour towards evidence-based health care. Quality Health Care 1997; 6: 205-211. 